\title{
Femoral migration of the cementless Oxford which caused the bearing dislocation: a report of two cases
}

\author{
Hiroshi Inui* D, Shuji Taketomi, Ryota Yamagami, Kohei Kawaguchi and Sakae Tanaka
}

\begin{abstract}
Background: There are no previous reports on the complications around the femoral component of cementless Oxford unicompartmental knee arthroplasty (UKA). However, we experienced two cases of femoral migration to the proximal side, which caused bearing dislocations after cementless Oxford UKA.

Case presentation: Case1. In an 82-year-old woman, bearing dislocation occurred 13 months postoperatively because of femoral migration that was resolved with an revision surgery to cemented component and thicker mobile insert.

Case2. In a 52-year-old man, first bearing dislocation occurred 7 months postoperatively. Five months after revising the insert to a thicker one, another dislocation occurred mainly because of the femoral migration. Eventually, a revision to total knee arthroplasty was necessary.

Conclusions: The inferred main reasons of femoral migration of cementless Oxford were osteoporosis for the first case and early return to high performance sports activity for the second case. Although several merits of using cementless prosthesis, particularly better fixation and lesser radiolucency than cemented prosthesis, have been reported, surgeons should pay attention to the patient's bone quality and advise a slow return to high-level physical activity.
\end{abstract}

Keywords: Unicompartmental knee arthroplasty, Oxford mobile bearing, Bearing dislocation, Cementless prosthesis, femoral migration

\section{Background}

Unicompartmental knee arthroplasty (UKA) is performed for the treatment of isolated unicompartmental knee disease. The Oxford Knee (Zimmer-Biomet, Swindon, United Kingdom), which features a fully congruent mobile bearing designed to minimize wear, has been in clinical use for $>40$ years $[1,2]$. Satisfactory results have been achieved with UKA in the medial compartment when strict inclusion criteria are followed $[3,4]$. However, UKA is associated with a significantly higher rate of revision as reported

\footnotetext{
*Correspondence: hiroshi_inu0707@yahoo.co.jp

Department of Orthopaedic Surgery, Faculty of Medicine, The University of Tokyo, 7-3-1 Hongo, Bunkyo-ku, Tokyo 113-0033, Japan
}

by several studies $[5,6]$. One of the reasons reported is the misinterpretation of radiolucent lines that are commonly observed around the cemented Oxford UKA [7]. Therefore, this led to the introduction of cementless version of Oxford UKA. The shape of the cementless prosthesis is identical to the cemented prosthesis, except the bottom surface having a porous titanium layer with calcium hydroxyapatite coating [8].

The cementless Oxford UKA is associated with a significant lower incidence of radiolucent lines than in cemented Oxford UKA, suggestive of an improved fixation [9]. Although there are several reports on the complications of the tibial side, such as valgus subsidence of the tibial component and tibial fractures, to the best of

(c) The Author(s). 2020 Open Access This article is licensed under a Creative Commons Attribution 4.0 International License which permits use, sharing, adaptation, distribution and reproduction in any medium or format, as long as you give appropriate credit to the original author(s) and the source, provide a link to the Creative Commons licence, and indicate if changes were made. The images or other third party material in this article are included in the article's Creative Commons licence, unless indicated otherwise in a credit line to the material. If material is not included in the article's Creative Commons licence and your intended use is not permitted by statutory regulation or exceeds the permitted use, you will need to obtain permission directly from the copyright holder. To view a copy of this licence, visit http://creativecommons.org/licenses/by/4.0/. The Creative Commons Public Domain Dedication waiver (http://creativecommons.org/publicdomain/zero/1.0/) applies to the data made available in this article, unless otherwise stated in a credit line to the data. 
our knowledge, there have been no reported cases of complication on the femoral side of cementless Oxford UKA $[10,11]$. Herein, we report two cases of femoral migration causing bearing dislocations after cementless Oxford UKA.

\section{Case presentation}

\section{Case 1}

An 82-year-old woman with anteromedial osteoarthritis of the right knee was treated with cementless Oxford UKA. The patient [body weight, $42 \mathrm{~kg}$; height, $149 \mathrm{~cm}$; and body mass index (BMI), $\left.18.9 \mathrm{~kg} / \mathrm{m}^{2}\right]$ had undergone cemented Oxford on the left knee 3 years ago because cementless Oxford was not introduced at that time. Her preoperative Knee Society Score [12] was 51 points and the Knee Society Functional Score was 55 points. The range of motion (ROM) of the right knee was $140^{\circ}$ flexion and $0^{\circ}$ extension.

During the surgery, a thigh tourniquet was applied and the leg was placed on a thigh support with the hip flexed about 30 degree. A minimally invasive approach was used. An incision was made from the medial pole of the patella to the medial side of the tibial tuberosity and was deepened through the joint capsule. At its upper end, capsular incision was extended proximally $1 \mathrm{~cm}$ into the vastus medialis. When performing osteotomy, tibial alignment was aimed at $90^{\circ}$ to the mechanical axis in the frontal plane and $7^{\circ}$ of the posterior slope in the sagittal plane, and femoral alignment was aimed at $90^{\circ}$ to the mechanical axis in the frontal plane and $10^{\circ}$ of flexion in the sagittal plane using Microplasty system [13]. In addition, we performed the gap balancing and implantation technique after the osteotomy procedures. The thickness of the mobile bearing was selected using the feeler gauge. The gauge thickness was thought to be appropriate when natural tension in the ligaments was achieved. Under these circumstances the feeler gauge would slide in and out easily but will not tilt. The cementless UKA was planned by an experienced surgeon (HI). However, during the surgery, we used cemented tibial component because we thought that the tibial bone quality was not good. A small-sized cementless femoral component and an A-size tibial cemented component with a 4-mm thick meniscal bearing were implanted. Intraoperatively, we confirmed the same gap balance between knee flexion and extension, and the anterior cruciate ligament was well tensioned and covered with synovial membrane. There were no abnormal movements of the meniscal bearing and no signs of bearing dislocation. The postoperative radiographs showed appropriate implantation (Fig. 1a).

Regarding postoperative rehabilitation, range of motion exercise and walking exercises first with a crutch and then a walker, were started on the first postoperative day. At 3 weeks postoperatively, the patient was discharged from our hospital and completed the rehabilitation protocol with physiotherapists.

At one-year postoperative follow-up, she felt no pain, and the Knee Society and Knee Society Functional Scores were 95 and 100 points, respectively. The ROM of the right knee was $140^{\circ}$ flexion and $0^{\circ}$ extension. She did not experience knee instability during her daily routine. Although radiography of the frontal plane showed migration of the femoral component, the radiographs showed no apparent loosening the femoral component, (Fig. 1b).

At 13 months postoperatively, she had sudden and severe knee pain while asleep. She could not walk, so she had to be brought to our facility in an ambulance. The meniscal bearing was posteriorly dislocated, as shown on the radiographic images (Fig. 2). We could

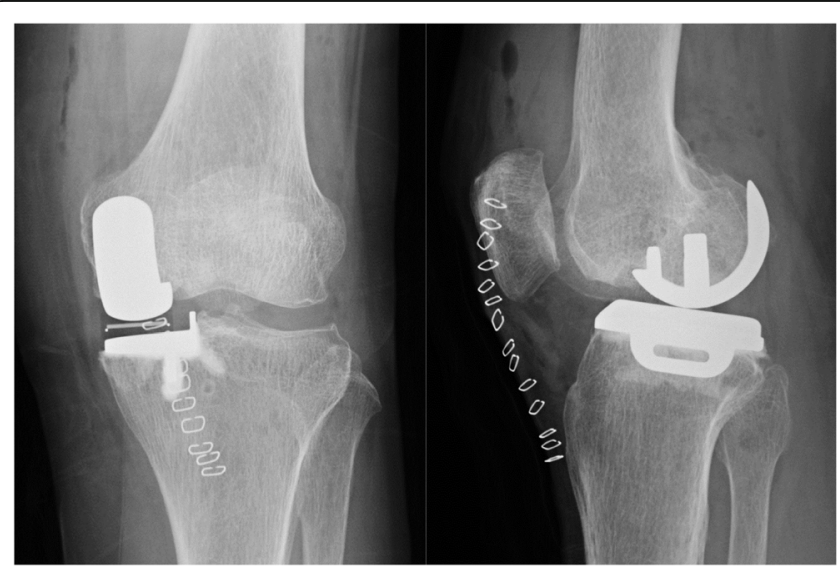

(A)

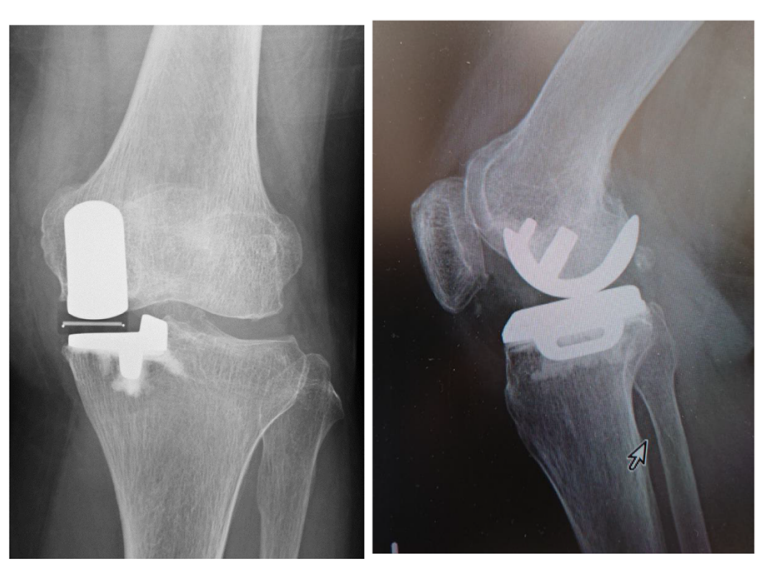

(B)

Fig. 1 Case 1 radiographs. Postoperative plain radiographs of the left knee. a Postoperative radiographs at 1 year showing the migration of the femoral component (b) 

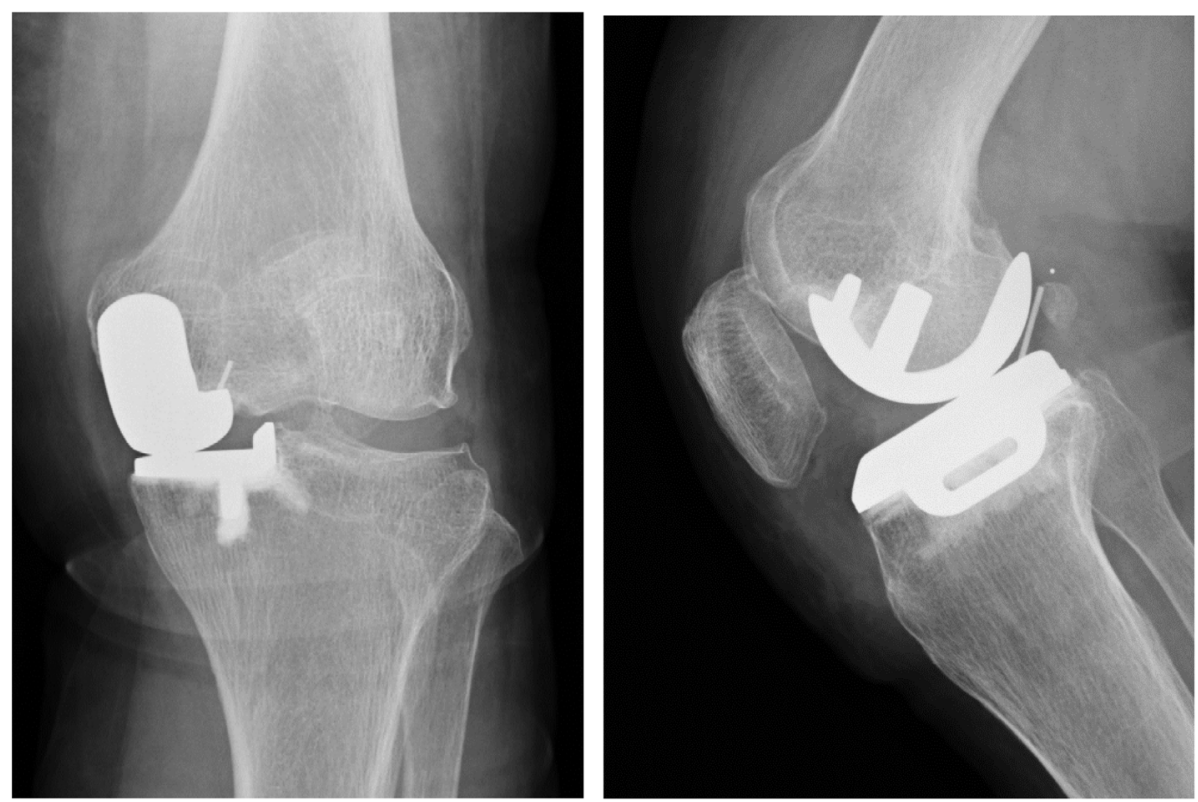

Fig. 2 Radiographs of case 1 showing the bearing posterior dislocation

not succeed in closed reduction; therefore, we performed surgical intervention. During the revision surgery, we observed the subsidence of the femoral component. The femoral component could easily be retrieved because of the loosening of the femoral component. In addition, there was no bone attached to the undersurface of the retrieved femoral component (Fig. 3). We implanted the same small-sized cemented Oxford femoral component, and the $8-\mathrm{mm}$ thick bearing was inserted (Fig. 4). One year after the revision of UKA, her knee was pain-free and had a ROM of $0^{\circ}$ extension to $140^{\circ}$ flexion. She had no femoral migration and bearing re-dislocation.

\section{Case 2}

The second case was a 52-year-old man (body weight, $101 \mathrm{~kg}$; height, $179 \mathrm{~cm}$; and BMI, $31.5 \mathrm{~kg} / \mathrm{m}^{2}$ ) with anteromedial osteoarthritis of the right knee. The preoperative Knee Society and Knee Society Functional Scores were 57 and 60 points, respectively. The ROM of the left knee was $125^{\circ}$ flexion and $5^{\circ}$ extension. The surgical technique used for Case 2 was the same as that used for Case 1. The patient had a good bone quality. Therefore, a medium-sized cementless femoral component and Dsized cementless tibial component with a 5-mm thick meniscal bearing were implanted. Intraoperatively, we confirmed the same gap balance between knee flexion and extension, and the anterior cruciate ligament was well-tensioned and covered with synovial membrane. There was no abnormal movement of the meniscal bearing or signs of bearing dislocation. The postoperative radiographs showed appropriate implantation (Fig. 5). Immediately after the operation, the pain disappeared, and he resumed playing Judo 6 weeks postoperatively. Seven months postoperatively, he had sudden and severe knee pain when he tried to ride a bicycle. The meniscal bearing was anteriorly dislocated as shown on the radiographic images (Fig. 6). During the additional surgery,

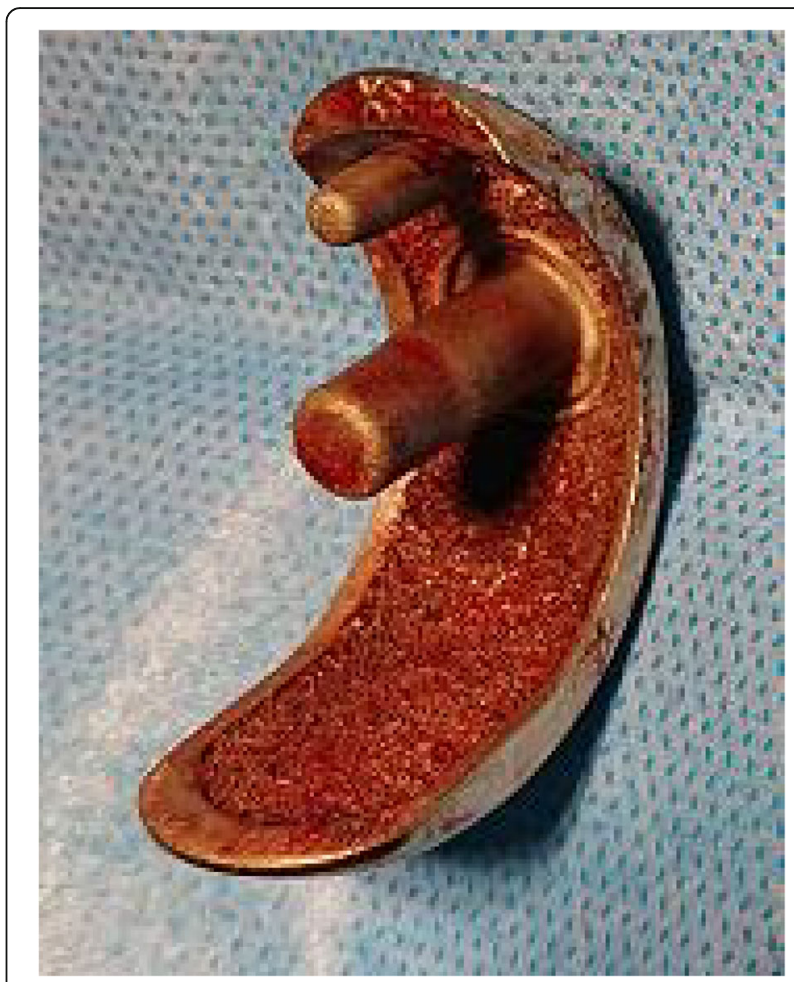

Fig. 3 Image of the retrieved femoral component. No bone is attached to the undersurface of the retrieved femoral component 


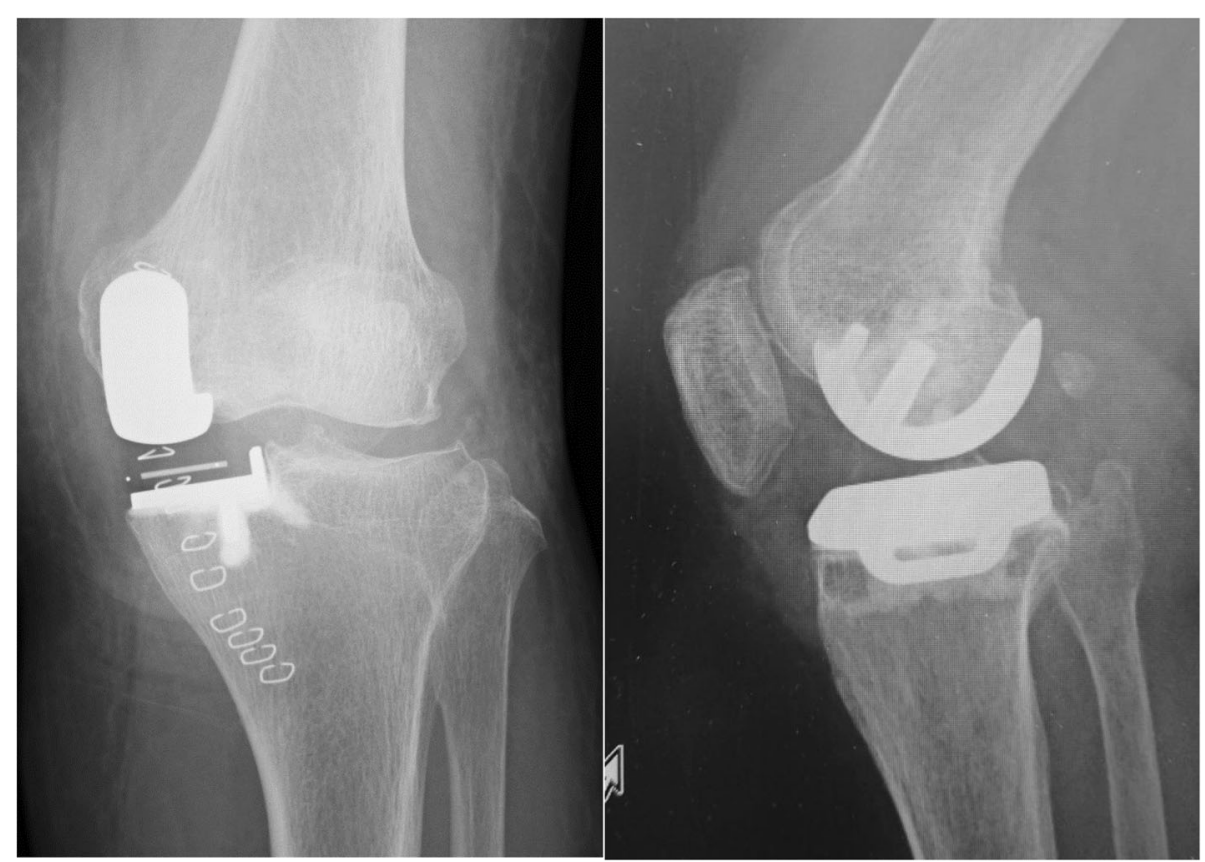

Fig. 4 Radiographs of case 1 after the revision surgery

although the tibial component slightly subsided anteriorly, there was no loosening of the tibial component. We did not check the fixation stability of the femoral component because we did not expect loosening of the femoral component. We changed the mobile bearing from 5- to 9-mm thickness and confirmed no signs of bearing dislocation intraoperatively. We observed femoral migration and radiolucent zone around the femoral pegs from the radiographic images taken postoperatively (Fig. 7). Five months after the additional surgery, he experienced another bearing anterior dislocation, so we performed revision surgery (Fig. 8a). During the surgery, the femoral component subsided approximately up to $4 \mathrm{~mm}$ and was loose enough to be easily retrieved using an
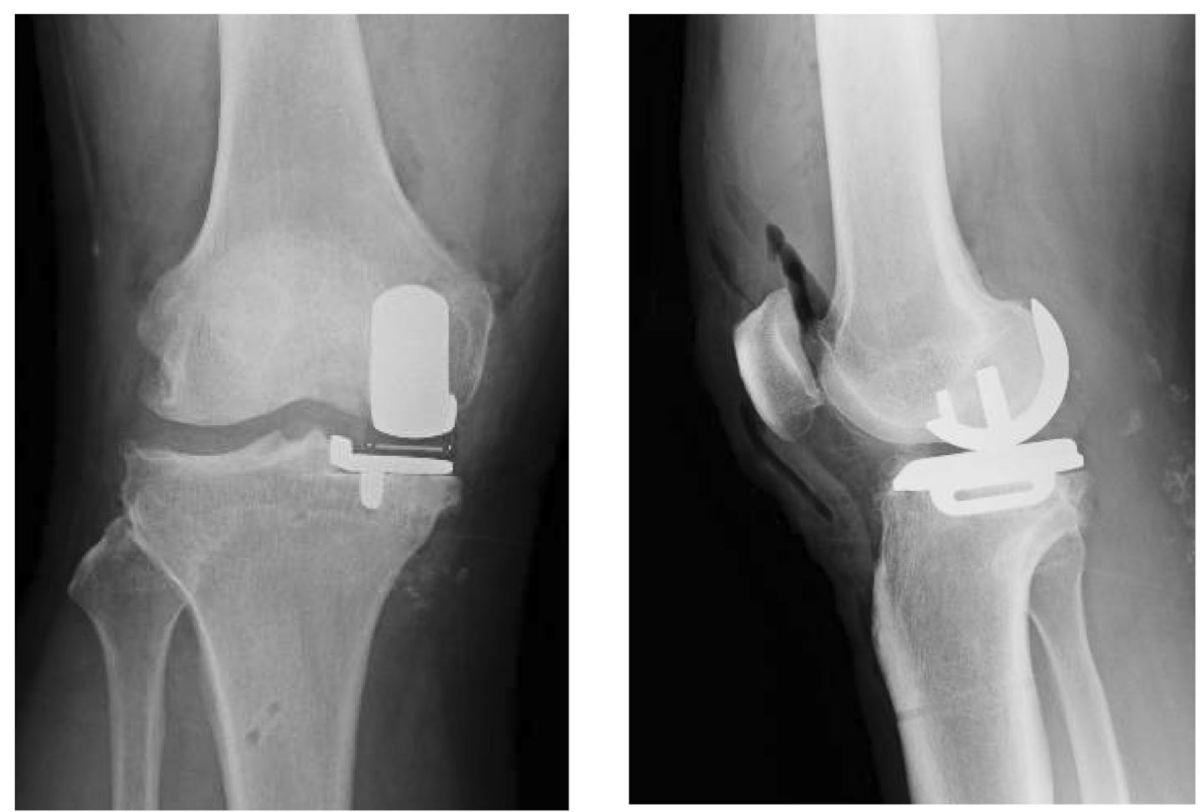

Fig. 5 Case 2 radiographs. Postoperative plain radiographs of the left knee 

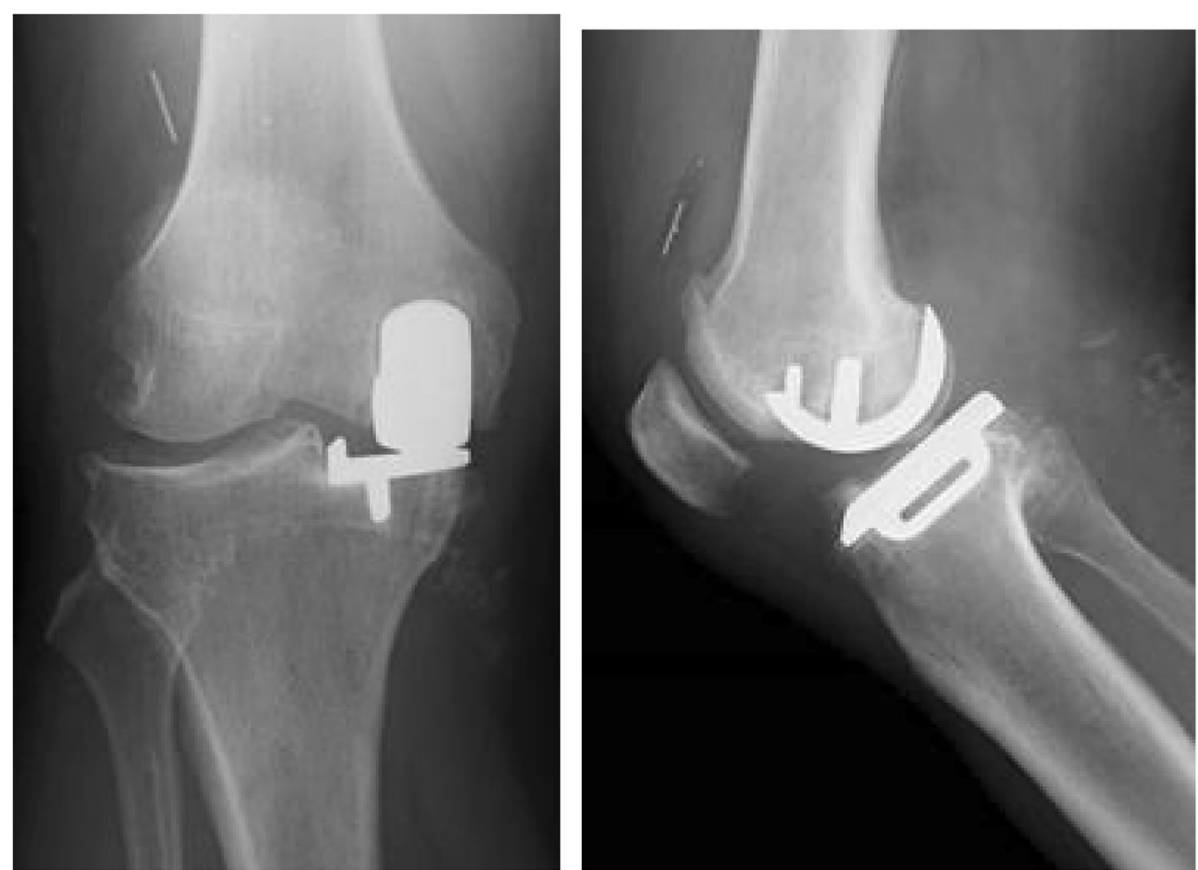

Fig. 6 Postoperative radiographs of case 2 at 6 months showing bearing dislocation

elevator. We retrieved the components and revised to total knee arthroplasty (Journey II BCS. Smith and Nephew, Memphis, TN, USA; Fig. 8b).

Judging from the clinical findings, laboratory data, the synovial cell count, and culture results of arthrocentesis of both cases, the onset of septic loosening was thought to be negative.
Both patients provided their consent for publication of their data.

\section{Discussion and conclusion}

To the best of our knowledge, this is the first report on the femoral migration of cementless Oxford causing bearing dislocations. We have performed 345 Oxford
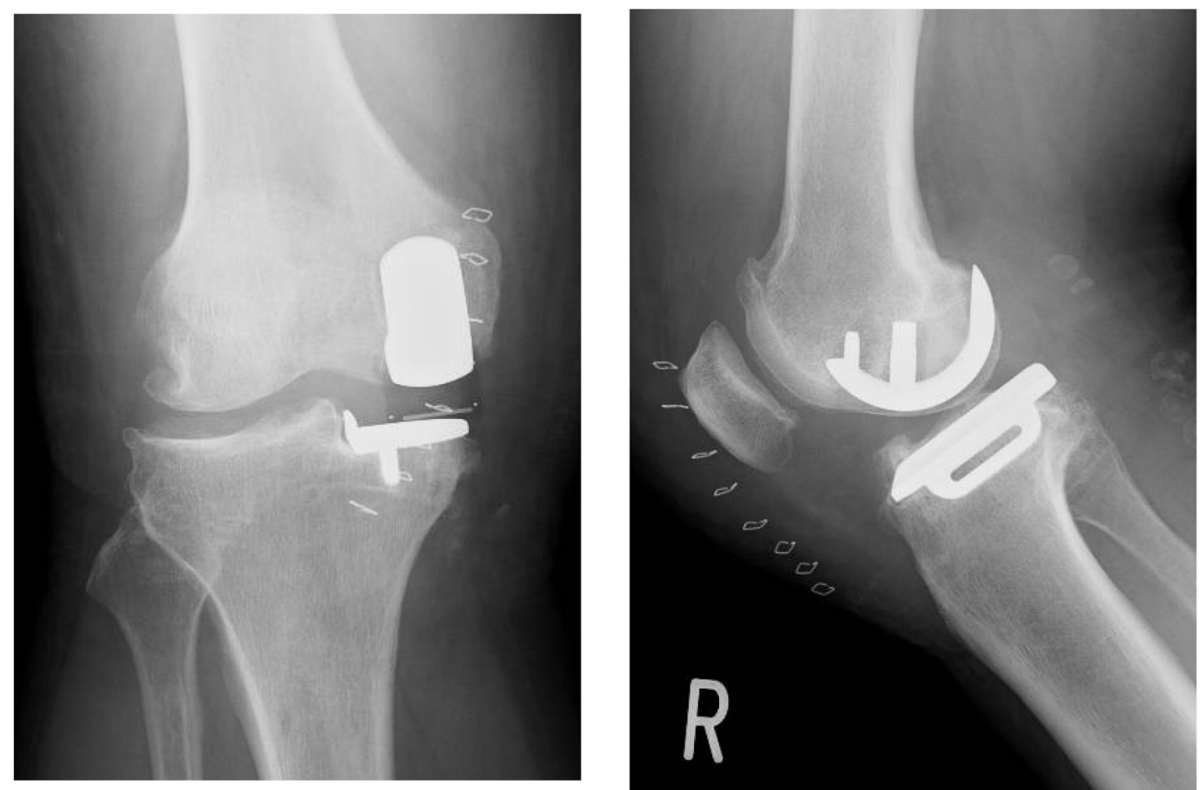

Fig. 7 Radiographs of case 2 after the additional surgery showing femoral migration and radiolucent zone around the femoral pegs 


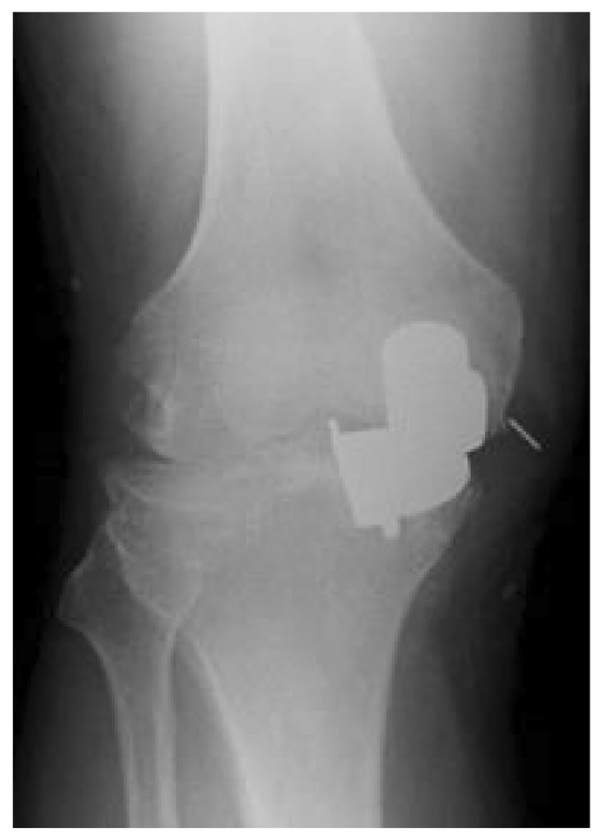

(A)

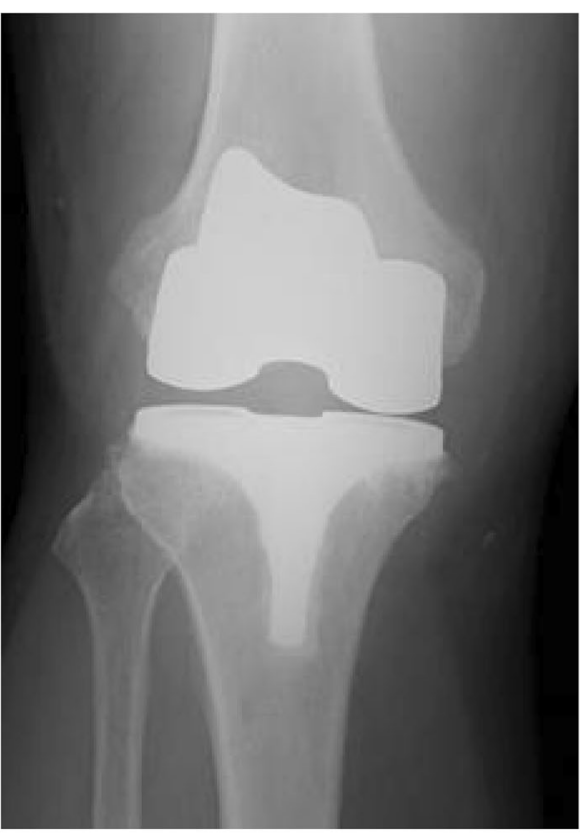

(B)

Fig. 8 Radiographs 5 months after the additional surgery shows bearing re-dislocation (a). Radiographs after the revision to total knee arthroplasty (b)

UKAs since 2011, and cementless femoral component has been used for 113 knees since 2016. Regarding the bearing dislocations, we experienced three cases (2.7\%) using cementless femoral prosthesis. One was a dislocation into the condylar ridge, whereas the other two cases were anterior and posterior bearing dislocations as mentioned in the present report. Conversely, among the 232 cases using cemented femoral component, we experienced only one bearing dislocation (0.5\%) into the condylar ridge and no anterior or posterior dislocations.

The causes of bearing dislocations into the condylar ridge are the inappropriate combination of the component sizes (small femur and AA-size tibia) and diagnosis (osteonecrosis), but no technical error [14]. Moreover, we experienced no anterior and posterior dislocation cases in the cemented Oxford series. Therefore, we confirmed that our surgical procedure of Oxford UKA was appropriate.

However, we experienced two cases of anterior and posterior bearing dislocations after using cementless prosthesis. During the revision surgery, we could not find any cause, including ligament damage, component malposition, and unretrieved bony spur or free body, other than the migration of the femoral components. We think that excessive migration of the femoral components enlarged the gaps between the femoral and tibial components and caused the dislocations of mobile bearing.

The cause of femoral migration was speculated to be poor bone quality in Case 1. We didn't perform the evaluation of bone quality preoperatively. After the revision surgery, dual-energy X-ray absorptiometry examination revealed a femoral neck bone mineral density of $0.386 \mathrm{mg} / \mathrm{cm}^{2}$ and the young adult mean of $68 \%$. Eckert et al. [15] have reported that bone quality is the key decision factor for selecting cemented or cementless UKA implant. Kerens et al. [8] reported that in their 60 consecutive cementless Oxford cases, they gave up using cementless femoral prosthesis in 8 cases because of inferior bone quality and implanted cemented prosthesis. Since our introduction of cementless Oxford in 2016, we have used cementless tibial component in about 30\% cases because the press-fit area in the cementless fixation is relatively small, and we are anxious about early loosening, particularly in patients with inferior bone quality. Conversely, we used cementless femoral prosthesis for almost all cases because the rigid fixation contributed by the two pegs and wide contact area between the bone and undersurface of the femoral component, which has a porous titanium layer with calcium hydroxyapatite coating. However, the femoral migration in Case 1 revealed the importance of the bone density of the femoral condyle.

Therefore, we should avoid using cementless prostheses for the femoral component, as well as for the tibial component, in those patients whose bone quality is poor.

In Case 2, it is difficult to surmise the causes because the patient was young and had a good bone quality. However, we speculate that one of the main reasons was 
his rapid return to aggressive sports. In fact, he was a famous Judo instructor and occasionally played Judo with Olympic level athletes. Kendrick et al. [16] have reported increased femoral migration of cementless Oxford up to 6 months, and thereafter, no significant additional migration. Excessive stress can enhance the risk of increased migration within 6 months postoperatively. Although Panzram et al. [17] reported 17 and 24 of 27 patients returned to sports within 3 and 6 months, respectively, after cementless Oxford UKA, we think that patients should not return to high performance sports until 6 months postoperatively, when migration reaches a plateau. Furthermore, obesity might be another reason for the migration. Obesity is a contraindication of Oxford UKA [18]; however, it is possible that obesity, in addition to early return to sports, may worsen the migration and lead to loosening and bearing dislocation.

Regarding the migration and subsidence of the tibial side of the cementless Oxford, several reasons other than poor bone quality and early return to sports have been reported, including impingement of the mobile bearing on the tibial wall, damage to the lateral part of the horizontal tibial surface, fracture of the posterior cortex during keel cut and tibial component malpositioning $[10,19]$. Therefore there might be some other reasons of the femoral migration of the current report.

There are several merits of employing cementless Oxford UKA, including shorter operative time, equivalent or superior clinical outcomes, and improved long-term fixation at the expense of short-term fixation $[8,9,15]$. Therefore, we currently use cementless Oxford UKA for the patients who are not diagnosed with osteoporosis or who do not wish an early return to high-level physical activity. We think we should use cemented Oxford for the patients who need rigid fixation just after the UKA procedure. Recently, we have not experienced the migration of cementless prosthesis in any case. However, further observations are necessary to decide the ideal inclusion criteria for using cementless Oxford UKA.

\section{Abbreviation}

UKA: unicompartmental knee arthroplasty

\section{Acknowledgements}

We thank Nancy Schatken, BS, MT(ASCP), from Edanz Group, for editing a draft of this manuscript (www.edanzediting.com/ac).

\section{Authors' contributions}

All authors have read and approved the manuscript. HI: The first author, corresponding author, Main surgeon of the two cases. ST: The second assistant of the second case. RY: The first assistant of the second case. KK: The first assistant of the first case. ST: The second assistant of the first case.

\section{Funding}

This case report did not receive any specific any grant from funding agencies in the public, commercial, or not-for-profit sectors.

\section{Availability of data and materials}

The datasets used during the current study are available from the corresponding author on reasonable request.

Ethics approval and consent to participate

Not applicable as the manuscript is a case report.

\section{Consent for publication}

A copy of the signed, written informed consent for publication form is available for review by the editor.

Participants (two patients) understand that the information will be published without their names attached but that full anonymity cannot be guaranteed. They understand that text and pictures published in the article will be freely available on the internet and may be seen by the general public. The pictures and text may also appear on other websites or in print, may be translated into other languages or used for commercial purposes.

\section{Competing interests}

No potential competing interest relevant to this article was reported.

Received: 28 April 2020 Accepted: 1 June 2020

Published online: 08 June 2020

\section{References}

1. Goodfellow JW, Tibrewal SB, Sherman KO, O'Connor JJ. Unicompartmental Oxford meniscal knee arthroplasty. J Arthroplast. 1987;2:1-9.

2. Kendrick BJ, Simpson DJ, Kaptein BL, Valstar ER, Gill HS, Murray DW, Price AJ. Polyethylene wear of mobile-bearing unicompartmental knee replacement at 20 years. J Bone Joint Surg Br. 2011;93:470.

3. Pandit H, Hamilton TW, Jenkins C, Mellon SJ, Dodd CA, Murray DW. The clinical outcome of minimally invasive phase 3 Oxford knee arthroplasty:a 15-year follow-up of 1000 UKAs. Bone Joint J. 2015;97:1493.

4. Yoshida K, Tada M, Yoshida H, Takei S, Fukuoka S, Nakamura H. Oxford phase3 unicompartmental knee arthroplasty in Japan-clinical results in greater than one thousand cases over ten years. J Arthroplast. 2013;28:168.

5. Liddle AD, Pandit $H$, Judge A, Murray DW. Optimal usage of unicompartmental knee arthroplasty: a study of 41,986 cases from the National Joint Registry for England and Wales. Bone Joint J. 2015;97:1506.

6. Baker PN, Petheram T, Avery PJ, Gregg PJ, Deehan DJ. Revision for unexplained pain following unicompartmental and total knee replacement. J Bone Joint Surg Am. 2012;94:e126.

7. Kendrick BJ, James AR, Pandit H, Gill HS, Price AJ, Blunn GW, Murray DW. Histology of the bone-cement interface in retrieved Oxford unicompartmental knee replacements. Knee. 2012;19:918-22.

8. Kerens B, Schotanus MGM, Boonen B, Boog P, Emans PJ, Lacroix H, Kort NP. Cementless versus cemented Oxford unicompartmental knee arthroplasty: early results of a non-designer user group. Knee Surg Sports Traumatol Arthrosc. 2017;25:703.

9. Pandit H, Liddle AD, Kendrick BJ, Jenkins C, Price AJ, Gill HS, Dodd CA, Murray DW. Improved fixation in cementless unicompartmental knee replacement: five-year results of a randomized controlled trial. J Bone Joint Surg Am. 2013;95:1365.

10. Liddle AD, Pandit HG, Jenkins C, Lobenhoffer P, Jackson WF, Dodd CA, Murray DW. Valgus subsidence of the tibial component in cementless Oxford unicompartmental knee replacement. Bone Joint J. 2014;96-B:345-9.

11. Mohammad HR, Campi S, Murray D, Mellon S. Instruments to reduce the risk of tibial fracture following cementless unicompartmental knee replacement. Knee. 2018;25:988-96.

12. Insall JN, Dorr LD, Scott RD, Scott WN. Rationale of the knee society clinical rating system. Clin Orthop Relat Res. 1989;248:13-4.

13. Hurst JM, Berend KR, Adams JB, et al. Radiograohic comparison of mobilebearing partial knee single-peg versus twin-peg design. J Arthroplast. 2015; 30:475-8.

14. Kawaguchi K, Inui H, Taketomi S, Yamagami R, Kono K, Nakazato K, Kawata M, Tanaka S. Meniscal bearing dislocation while rolling over in sleep following Oxford medial unicompartmental knee arthroplasty. Knee. 2019;26:267.

15. Eckert JA, Jaeger S, Klotz MC, Schwarze M, Bitsch RG. Can intraoperative measurement of bone quality help in decision making for cementless unicompartmental knee arthroplasty? Knee. 2018;25:609. 
16. Kendrick BJ, Kaptein BL, Valstar ER, Gill HS, Jackson WF, Dodd CA, Price AJ, Murray DW. Cemented versus cementless Oxford unicompartmental knee arthroplasty using radiostereometric analysis: a randomised controlled trial. Bone Joint J. 2015:97-B:185.

17. Panzram B, Bertlich I, Reiner T, Walker T, Hagmann S, Gotterbarm T.

Cementless unicompartmental knee replacement allows early return to normal activity. BMC Musculoskelet Disord. 2018;19:18.

18. Hamilton TW, Pandit HG, Jenkins C, Mellon SJ, Dodd CAF, Murray DW. Evidence-based indications for Mobile-bearing Unicompartmental knee Arthroplasty in a consecutive cohort of thousand knees. J Arthroplast. 2017:32:1779

19. Kamenaga T, Hiranaka T, Nakanishi Y, Yakayama K, Kuroda R, Matsumoto T. Valgus subsidence of the tibial component caused by tibial component malpositioning in cementless Oxford mobile-bearing unicompartmental knee arthroplasty. J Arthroplast. 2019;34:3054-60

\section{Publisher's Note}

Springer Nature remains neutral with regard to jurisdictional claims in published maps and institutional affiliations.

Ready to submit your research? Choose BMC and benefit from:

- fast, convenient online submission

- thorough peer review by experienced researchers in your field

- rapid publication on acceptance

- support for research data, including large and complex data types

- gold Open Access which fosters wider collaboration and increased citations

- maximum visibility for your research: over $100 \mathrm{M}$ website views per year

At BMC, research is always in progress.

Learn more biomedcentral.com/submissions 